\title{
A Practical Framework for Understanding and Reducing Medical Overuse: Conceptualizing Overuse Through the Patient-Clinician Interaction
}

\author{
Daniel J. Morgan, MD, MS ${ }^{1}$, Aaron L. Leppin, MD, MS², Cynthia D. Smith, MD³, Deborah Korenstein, MD*
}

'VA Maryland Healthcare System, University of Maryland School of Medicine and Centers for Disease Dynamics, Economics, and Policy, Baltimore, Maryland; 'Knowledge and Evaluation Research Unit, Mayo Clinic, Rochester, Minnesota; ${ }^{3}$ American College of Physicians, Philadelphia, Pennsylvania; ${ }^{4}$ Department of Medicine, Memorial Sloan Kettering Cancer Center, New York, New York.

Overuse of medical services is an increasingly recognized driver of poor-quality care and high cost. A practical framework is needed to guide clinical decisions and facilitate concrete actions that can reduce overuse and improve care. We used an iterative, expert-informed, evidence-based process to develop a framework for conceptualizing interventions to reduce medical overuse. Given the complexity of defining and identifying overused care in nuanced clinical situations and the need to define care appropriateness in the context of an individual patient, this framework conceptualizes the patient-clinician interaction as the nexus of decisions regarding inappropriate care. This interaction is influenced by other utilization drivers, including healthcare system factors, the practice environment, the culture of professional medicine, the culture of healthcare consumption, and individual patient and clinician factors. The variable strength of the evidence supporting these domains highlights important areas for further investigation. Journal of Hospital Medicine 2017;12:346351. (C) 2017 Society of Hospital Medicine
Medical services overuse is the provision of healthcare services for which there is no medical basis or for which harms equal or exceed benefits. ${ }^{1}$ This overuse drives poor-quality care and unnecessary cost. ${ }^{2,3}$ The high prevalence of overuse is recognized by patients, ${ }^{4}$ clinicians, ${ }^{5}$ and policymakers. ${ }^{6}$ Initiatives to reduce overuse have targeted physicians, ${ }^{7}$ the public, ${ }^{8}$ and medical educators ${ }^{9}, 10$ but have had limited impact. ${ }^{11,12}$ Few studies have addressed methods for reducing overuse, and de-implementation of nonbeneficial practices has proved challenging. ${ }^{1,13,14}$ Models for reducing overuse are only theoretical ${ }^{15}$ or are focused on administrative decisions. ${ }^{16,17}$ We think a practical framework is needed. We used an iterative process, informed by expert opinion and discussion, to design such a framework.

\section{METHODS}

The authors, who have expertise in overuse, value, medical education, evidence-based medicine, and implementation science, reviewed related conceptual frameworks ${ }^{18}$ and evidence regarding drivers of overuse. We organized these drivers into domains to create a draft framework, which we presented at Preventing Overdiagnosis 2015, a meeting of clinicians, patients, and policymakers interested in overuse. We incorporated feedback from meeting attendees to modify framework domains, and we performed structured searches (using key words in Pubmed) to explore, and estimate the

\footnotetext{
*Address for correspondence and reprint requests: Deborah Korenstein, MD, Department of Medicine, Memorial Sloan Kettering Cancer Center, 485 Lexington Ave, New York, NY 10017; Telephone: 646-888-8139; Fax: 646-2277102; E-mail: korenstd@mskcc.org
}

Received: September 15, 2016; Revised: October 26, 2016; Accepted: November 10, 2016

2017 Society of Hospital Medicine DOI 10.12788/jhm.2738 strength of, evidence supporting items within each domain. We rated supporting evidence as strong (studies found a clear correlation between a factor and overuse), moderate (evidence suggests such a correlation or demonstrates a correlation between a particular factor and utilization but not overuse per se), weak (only indirect evidence exists), or absent (no studies identified evaluating a particular factor). All authors reached consensus on ratings.

\section{Framework Principles and Evidence}

Patient-centered definition of overuse. During framework development, defining clinical appropriateness emerged as the primary challenge to identifying and reducing overuse. Although some care generally is appropriate based on strong evidence of benefit, and some is inappropriate given a clear lack of benefit or harm, much care is of unclear or variable benefit. Practice guidelines can help identify overuse, but their utility may be limited by lack of evidence in specific clinical situations, ${ }^{19}$ and their recommendations may apply poorly to an individual patient. This presents challenges to using guidelines to identify and reduce overuse.

Despite limitations, the scope of overuse has been estimated by applying broad, often guideline-based, criteria for care appropriateness to administrative data. ${ }^{20}$ Unfortunately, these estimates provide little direction to clinicians and patients partnering to make usage decisions. During framework development, we identified the importance of a patient-level, patient-specific definition of overuse. This approach reinforces the importance of meeting patient needs while standardizing treatments to reduce overuse. A patient-centered approach may also assist professional societies and advocacy groups in developing actionable campaigns and may uncover evidence gaps.

Centrality of patient-clinician interaction. During framework development, the patient-clinician interaction emerged as 
TABLE 1. Factors That Contribute to Each Domain of the Framework for Overuse Of Care ${ }^{a}$

\begin{tabular}{|c|c|c|c|c|}
\hline Domain & Factors & Evidence & Specific Impact & $\begin{array}{l}\text { Likely Magnitude of } \\
\text { Effect on Overuse }\end{array}$ \\
\hline $\begin{array}{l}\text { Culture of healthcare } \\
\text { consumption }\end{array}$ & $\begin{array}{l}\text { Consumerism and advocating for one's own health } \\
\text { Information found on the internet and through the media } \\
\text { General expectations about the appropriate amount and } \\
\text { type of care } \\
\text { Belief that you get what you pay for }\end{array}$ & $\begin{array}{l}\text { Strength: weak } \\
\text { None related to specific factors. } \\
\text { Evidence related to: } \\
\text { Variations in care }{ }^{27,55} \\
\text { General enthusiasm for screening }\end{array}$ & $\begin{array}{l}\text { Likely leads to more general } \\
\text { utilization, overuse, and use of } \\
\text { costlier alternatives }\end{array}$ & Moderate \\
\hline $\begin{array}{l}\text { Patient factors and } \\
\text { experiences }\end{array}$ & $\begin{array}{l}\text { Prior healthcare experiences (patient and family) } \\
\text { Demographic factors and education } \\
\text { Health literacy and numeracy } \\
\text { Patient interactions with health center staff } \\
\text { Patient interactions with other clinicians }\end{array}$ & $\begin{array}{l}\text { Strength: weak to strong } \\
\text { Evidence related to: } \\
\text { Impact of race/ethnicity on overuse and } \\
\text { underuse }{ }^{57,58} \\
\text { Patient expectations }{ }^{59,60} \\
\text { Patient desire for investigation and answers }{ }^{61}\end{array}$ & $\begin{array}{l}\text { Variable; can contribute to overuse } \\
\text { or protect against overuse }\end{array}$ & $\begin{array}{l}\text { Moderate } \\
\text { Interventions related to with } \\
\text { patient demographics not } \\
\text { defined }\end{array}$ \\
\hline $\begin{array}{l}\text { Culture of } \\
\text { professional } \\
\text { medicine }\end{array}$ & $\begin{array}{l}\text { Influence of broad regulations and metrics } \\
\text { Value placed on finding answers, certainty } \\
\text { Value placed on doing things } \\
\text { Discomfort with discussing/admitting diagnostic } \\
\text { uncertainty to others (strong vs. weak) } \\
\text { Fear of missing diagnoses } \\
\text { New high tech solutions more valued and reimbursed. }\end{array}$ & $\begin{array}{l}\text { Strength: absent to moderate } \\
\text { No evidence exploring role of most individual } \\
\text { factors. } \\
\text { Evidence related to: } \\
\text { Association between local culture and } \\
\text { overuse }^{62-64} \text { (moderate evidence) } \\
\text { Physician factors and geographic variations }\end{array}$ & $\begin{array}{l}\text { Overuse performance measures } \\
\text { can limit overuse but measures } \\
\text { for preventing underuse may lead } \\
\text { to overuse } \\
\text { Emphasis on certainty, technology } \\
\text { and active intervention likely } \\
\text { contribute to overuse }\end{array}$ & Moderate to high \\
\hline $\begin{array}{l}\text { Clinician attitudes } \\
\text { and beliefs }\end{array}$ & $\begin{array}{l}\text { Personality and personal biases } \\
\text { Poor numeracy and knowledge of evidence } \\
\text { Past experiences with other patients with the same } \\
\text { condition } \\
\text { Knowledge of and attitudes toward particular patient } \\
\text { Fear of litigation (defensive medicine) } \\
\text { Clinician-clinician interactions } \\
\text { Clinician-staff interactions } \\
\text { Comfort with discussing cost or other issues } \\
\text { Discomfort with diagnostic uncertainty }\end{array}$ & $\begin{array}{l}\text { Strength: weak } \\
\text { Evidence related to: } \\
\text { Physician beliefs and geographic variations }{ }^{28} \\
\text { Variation in utilization based on specific physician } \\
\text { characteristics } \\
\text { Self-68 }\end{array}$ & $\begin{array}{l}\text { Traditionally mostly push toward } \\
\text { more care } \\
\text { Poor numeracy, lack of knowledge, } \\
\text { discomfort with uncertainty, } \\
\text { sampling biases from past } \\
\text { experiences, interactions with other } \\
\text { clinicians, fear of litigation, and } \\
\text { some personality traits likely lead } \\
\text { to overuse } \\
\text { Patient continuity helps prevent } \\
\text { overuse }\end{array}$ & High \\
\hline $\begin{array}{l}\text { Practice } \\
\text { environment }\end{array}$ & $\begin{array}{l}\text { Financial incentives } \\
\text { Practice norms within the group and expectations from } \\
\text { the affiliated health system } \\
\text { Structures which influence specific practices } \\
\text { Risk of lawsuits } \\
\text { Performance metrics may encourage overuse }\end{array}$ & $\begin{array}{l}\text { Strength: weak } \\
\text { Practice norms not well studied } \\
\text { Evidence related to: } \\
\text { Local cultural norms and aggressive care }{ }^{69-71} \\
\text { Residency training and utilization }{ }^{29,72,73} \\
\text { Financial incentives }{ }^{41,74} \text { (weak evidence) } \\
\text { General influence of practice setting }{ }^{75} \\
\text { Quality metrics may encourage too much care and } \\
\text { overuse }^{76,77}\end{array}$ & $\begin{array}{l}\text { Local cultural norms are influential } \\
\text { (including local training culture) } \\
\text { Other factors vary based on } \\
\text { specifics }\end{array}$ & High \\
\hline $\begin{array}{l}\text { The patient-clinician } \\
\text { interaction }\end{array}$ & $\begin{array}{l}\text { Specific communication styles } \\
\text { Concordance of culture, race, language, and gender } \\
\text { Prior experiences with each other } \\
\text { Visit priorities }\end{array}$ & $\begin{array}{l}\text { Strength: moderate for shared decision making, } \\
\text { continuity, weak for other factors } \\
\text { Evidence related to: } \\
\text { Continuity of care and overuse }{ }^{21} \\
\text { Continuity of care and utilization }{ }^{22,23} \\
\text { Communication }{ }^{24} \\
\text { Shared decision making and } \text { overuse }^{25}\end{array}$ & $\begin{array}{l}\text { Continuity of care likely reduces } \\
\text { overuse } \\
\text { Shared decision making likely } \\
\text { reduces overuse } \\
\text { Unclear impact of culture and } \\
\text { language }\end{array}$ & High \\
\hline
\end{tabular}

a Likely magnitude of effect on overuse was determined by author consensus based on strength and breadth of evidence and other factors.

the nexus through which drivers of overuse exert influence. The centrality of this interaction has been demonstrated in studies of the relationship between care continuity and overuse ${ }^{21}$ or utilization, ${ }^{22,23}$ by evidence that communication and patient-clinician relationships affect utilization, ${ }^{24}$ and by the observation that clinician training in shared decision-making reduces overuse. ${ }^{25} \mathrm{~A}$ patient-centered framework assumes that, at least in the weighing of clinically reasonable options, a patient-centered approach optimizes outcomes for that patient.

Incorporating drivers of overuse. We incorporated drivers of overuse into domains and related them to the patient-clinician interaction. ${ }^{26}$ Domains included the culture of healthcare consumption, patient factors and experiences, the practice environment, the culture of professional medicine, and clinician attitudes and beliefs.

We characterized the evidence illustrating how drivers within each domain influence healthcare use. The evidence 
for each domain is listed in Table 1.

\section{RESULTS}

The final framework is shown in the Figure. Within the healthcare system, patients are influenced by the culture of healthcare consumption, which varies within and among countries. ${ }^{27}$ Clinicians are influenced by the culture of medical care, which varies by practice setting, ${ }^{28}$ and by their training environment..$^{29}$ Both clinicians and patients are influenced by the practice environment and by personal experiences. Ultimately, clinical decisions occur within the specific patient-clinician interaction. ${ }^{24}$ Table 1 lists each domain's components, likely impact on overuse, and estimated strength of supporting evidence. Interventions can be conceptualized within appropriate domains or through the interaction between patient and clinician.

\section{DISCUSSION}

We developed a novel and practical conceptual framework for characterizing drivers of overuse and potential intervention

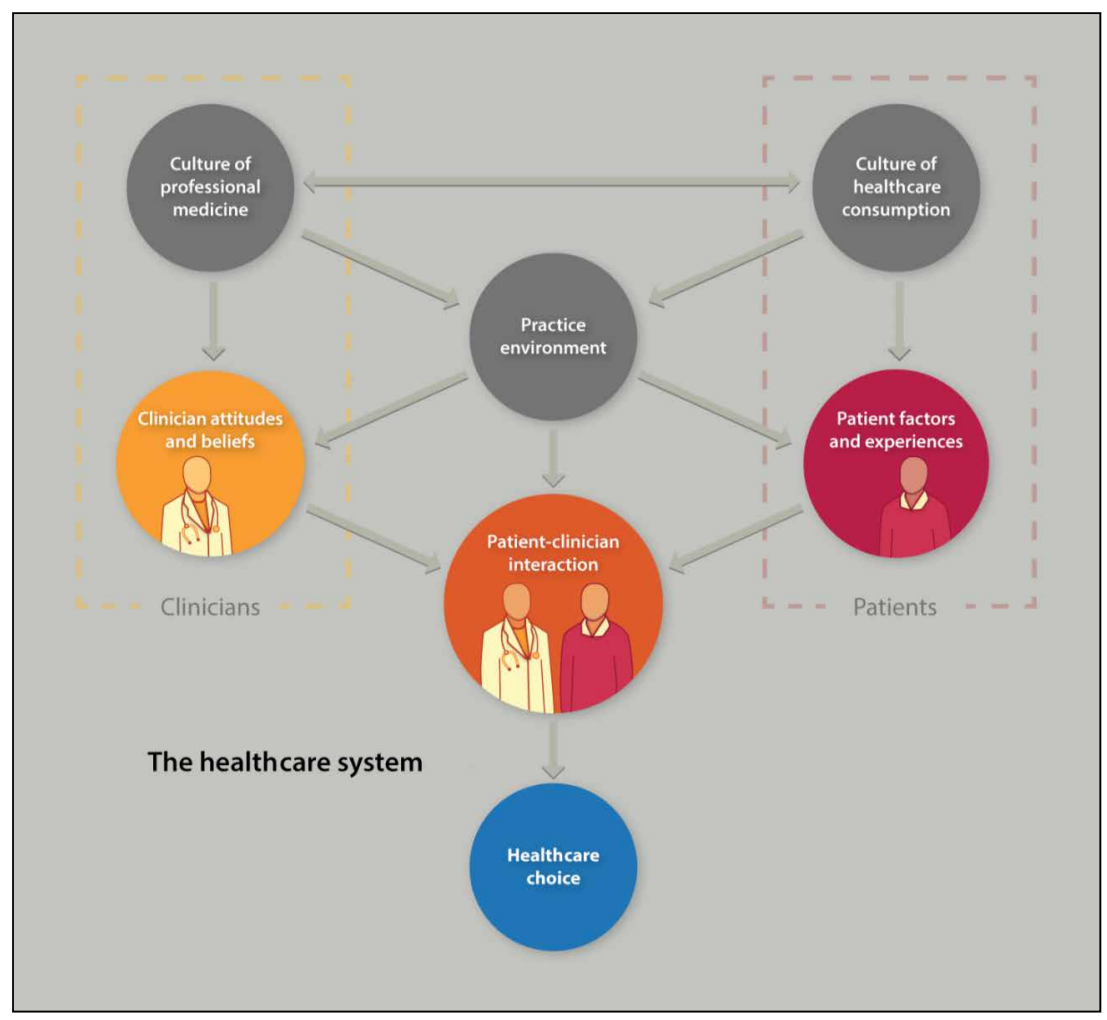

FIG. Framework for understanding and reducing overuse. points. To our knowledge, this is the first framework incorporating a patient-specific approach to overuse and emphasizing the patient-clinician interaction. Key strengths of framework development are inclusion of a range of perspectives and characterization of the evidence within each domain. Limitations include lack of a formal systematic review and broad, qualitative assessments of evidence strength. However, we believe this framework provides an important conceptual foundation for the study of overuse and interventions to reduce overuse.

\section{Framework Applications}

This framework, which highlights the many drivers of overuse, can facilitate understanding of overuse and help conceptualize change, prioritize research goals, and inform specific interventions. For policymakers, the framework can inform efforts to reduce overuse by emphasizing the need for complex interventions and by clarifying the likely impact of interventions targeting specific domains. Similarly, for clinicians and quality improvement professionals, the framework can ground root cause analyses of overuse-related problems and inform allocation of limited resources. Finally, the relatively weak evidence on the role of most acknowledged drivers of overuse suggests an important research agenda. Specifically, several pressing needs have been identified: defining relevant physician and patient cultural factors, investigating interventions to impact culture, defining practice environment features that optimize care appropriateness, and describing specific patient-clinician interaction practices that minimize overuse while providing needed care.

\section{Targeting Interventions}

Domains within the framework are influenced by different types of interventions, and different stakeholders may target different domains. For example:

- The culture of healthcare consumption may be influenced through public education (eg, Choosing Wisely ${ }^{\circledR}$ patient resources) $)^{30-32}$ and public health campaigns.

- The practice environment may be influenced by initiatives to align clinician incentives, ${ }^{33}$ team care, ${ }^{34}$ electronic health record interventions, ${ }^{35}$ and improved access. ${ }^{36}$

- Clinician attitudes and beliefs may be influenced by audit and feedback,$^{37-40}$ reflection, ${ }^{41}$ role modeling, ${ }^{42}$ and education. ${ }^{43-45}$

- Patient attitudes and beliefs may be influenced by education, access to price and quality information, and increased engagement in care. .6, $^{47}$

- For clinicians, the patient-clinician interaction can be improved through training in communication and shared decision-making, ${ }^{25}$ through access to information (eg, costs) that can be easily shared with patients, ${ }^{48,49}$ and through novel visit structures (eg, scribes). ${ }^{50}$

- On the patient side, this interaction can be optimized with improved access (eg, through telemedicine) $)^{51,52}$ or with patient empowerment during hospitalization.

- The culture of medicine is difficult to influence. Change likely will occur through:

- Regulatory interventions (eg, Transforming Clinical Practice Initiative of Center for Medicare \& Medicaid Innovation). 
TABLE 2. Using the Framework for Real-Life Examples of Overuse to Identify Practical Ways in Which Overuse Can Be Addressed

\begin{tabular}{|c|c|c|}
\hline Example of overuse & Possible Drivers/Domains & Feasible Approaches to Improvement \\
\hline $\begin{array}{l}\text { A hospitalist on a general medical service } \\
\text { wants to reduce use of routine lab testing }\end{array}$ & $\begin{array}{l}\text { Culture of health care: expectation of all clinicians (including attendings, consultants, } \\
\text { nursing) for daily lab testing } \\
\text { Clinician factors: belief that more is better, poor knowledge of evidence } \\
\text { Practice environment: ease of daily ordering in the EMR } \\
\text { Patient factors: expectation for frequent testing (likely a minor factor) }\end{array}$ & $\begin{array}{l}\text { Culture: broad campaign across the medical center } \\
\text { Clinician: education about evidence/guidelines }{ }^{43,44} \\
\text { Practice environment: EMR alert }{ }^{35}\end{array}$ \\
\hline $\begin{array}{l}\text { A physician hospital leader wishes } \\
\text { to reduce inpatient opioid prescribing }\end{array}$ & $\begin{array}{l}\text { Clinician factors: misperception of patient/parent desires, discomfort with pain } \\
\text { treatment }{ }^{81} \\
\text { Practice environment: pressure to discharge patients leading to aggressive pain } \\
\text { treatment } \\
\text { Patient factors: poor understanding of the potential harms of opioids, demand } \\
\text { Patient-clinician interaction: poor communication regarding pain itself and the } \\
\text { benefits/harms of therapy }\end{array}$ & $\begin{array}{l}\text { Clinician: education about guidelines/evidence }{ }^{43,44} \\
\text { Patient: provide information about options for treating pain and } \\
\text { potential opioid harms } \\
\text { Patient-clinician interaction: physician-directed tool for } \\
\text { communicating about the issue }\end{array}$ \\
\hline $\begin{array}{l}\text { A palliative care fellow seeks to reduce } \\
\text { imaging tests in EOL hospitalized patients }\end{array}$ & $\begin{array}{l}\text { Culture of healthcare: need to define clinical problems even if there is no intervention, } \\
\text { discomfort with doing nothing } \\
\text { Clinician factors: belief that more information helps patients, belief that patients desire } \\
\text { testing } \\
\text { Patient factors: poor knowledge or acceptance of prognosis } \\
\text { Patient-clinician interaction: poor communication regarding prognosis and EOL } \\
\text { preferences }\end{array}$ & $\begin{array}{l}\text { Clinician factors: education about harms of testing in these patients } \\
\text { Patient-clinician interaction: specific tools to improve } \\
\text { communication about EOL preferences }{ }^{49,78}\end{array}$ \\
\hline
\end{tabular}

NOTE: Abbreviations: EMR, electronic medical record; EOL, end of life.

- Educational initiatives (eg, high-value care curricula of Alliance for Academic Internal Medicine/American College of Physicians $\left.{ }^{53}\right)$.

- Medical journal features (eg, "Less Is More" in JAMA Internal Medicine $e^{54}$ and "Things We Do for No Reason" in Journal of Hospital Medicine).

○ Professional organizations (eg, Choosing Wisely ${ }^{\circledR}$ ).

As organizations implement quality improvement initiatives to reduce overuse of services, the framework can be used to target interventions to relevant domains. For example, a hospital leader who wants to reduce opioid prescribing may use the framework to identify the factors that encourage prescribing in each domain-poor understanding of pain treatment (a clinician factor), desire for early discharge encouraging overly aggressive pain management (an environmental factor), patient demand for opioids combined with poor understanding of harms (patient factors), and poor communication regarding pain (a patient-clinician interaction factor). Although not all relevant factors can be addressed, their classification by domain facilitates intervention, in this case perhaps leading to a focus on clinician and patient education on opioids and development of a practical communication tool that targets 3 domains. Table 2 lists ways in which the framework informs approaches to this and other overused services in the hospital setting. Note that some drivers can be acknowledged without identifying targeted interventions.

\section{Moving Forward}

Through a multi-stakeholder iterative process, we developed a practical framework for understanding medical overuse and interventions to reduce it. Centered on the patient-cli- nician interaction, this framework explains overuse as the product of medical and patient culture, the practice environment and incentives, and other clinician and patient factors. Ultimately, care is implemented during the patientclinician interaction, though few interventions to reduce overuse have focused on that domain.

Conceptualizing overuse through the patient-clinician interaction maintains focus on patients while promoting population health that is both better and lower in cost. This framework can guide interventions to reduce overuse in important parts of the healthcare system while ensuring the final goal of high-quality individualized patient care.

\section{Acknowledgments}

The authors thank Valerie Pocus for helping with the artistic design of Framework. An early version of Framework was presented at the 2015 Preventing Overdiagnosis meeting in Bethesda, Maryland.

Disclosures: Dr. Morgan received research support from the VA Health Services Research (CRE 12-307), Agency for Healthcare Research and Quality (AHRQ) (K08- HS18111). Dr. Leppin's work was supported by CTSA Grant Number UL1 TR000135 from the National Center for Advancing Translational Sciences, a component of the National Institutes of Health (NIH). Dr. Korenstein's work on this paper was supported by a Cancer Center Support Grant from the National Cancer Institute to Memorial Sloan Kettering Cancer Center (award number P30 CA008748). Dr. Morgan provided a self-developed lecture in a 3M-sponsored series on hospital epidemiology and has received honoraria for serving as a book and journal editor for Springer Publishing. Dr. Smith is employed by the American College of Physicians and owns stock in Merck, where her husband is employed. The other authors report no potential conflicts of interest.

\section{References}

1. Morgan DJ, Brownlee S, Leppin AL, et al. Setting a research agenda for medical overuse. BMJ. 2015;351:h4534.

2. Hood VL, Weinberger SE. High value, cost-conscious care: an international imperative. Eur J Intern Med. 2012;23(6):495-498. 
3. Korenstein D, Falk R, Howell EA, Bishop T, Keyhani S. Overuse of health care services in the United States: an understudied problem. Arch Intern Med. 2012;172(2):171-178.

4. How SKH, Shih A, Lau J, Schoen C. Public Views on U.S. Health System Organization: A Call for New Directions. http://www.commonwealthfund.org/publications/ data-briefs/2008/aug/public-views-on-u-s--health-system-organization--a-call-for new-directions. Published August 1, 2008. Accessed December 11, 2015

5. Sirovich BE, Woloshin S, Schwartz LM. Too little? Too much? Primary care physicians views on US health care: a brief report. Arch Intern Med. 2011;171(17):1582-1585.

6. Joint Commission, American Medical Association-Convened Physician Consortium for Performance Improvement. Proceedings From the National Summit on Overuse. https://www.jointcommission.org/assets/1/6/National_Summit_Overuse. pdf. Published September 24, 2012. Accessed July 8, 2016.

7. Cassel CK, Guest JA. Choosing Wisely: helping physicians and patients make smart decisions about their care. JAMA. 2012;307(17):1801-1802.

8. Wolfson D, Santa J, Slass L. Engaging physicians and consumers in conversations about treatment overuse and waste: a short history of the Choosing Wisely campaign. Acad Med. 2014;89(7):990-995.

9. Smith CD, Levinson WS. A commitment to high-value care education from the internal medicine community. Ann Int Med. 2015;162(9):639-640.

10. Korenstein D, Kale M, Levinson W. Teaching value in academic environments: shifting the ivory tower. JAMA. 2013;310(16):1671-1672.

11. Kale MS, Bishop TF, Federman AD, Keyhani S. Trends in the overuse of ambulatory health care services in the United States. JAMA Intern Med. 2013;173(2): 142-148.

12. Rosenberg A, Agiro A, Gottlieb M, et al. Early trends among seven recommendations from the Choosing Wisely campaign. JAMA Intern Med. 2015;175(12):1913 1920

13. Prasad V, Ioannidis JP. Evidence-based de-implementation for contradicted, un proven, and aspiring healthcare practices. Implement Sci. 2014;9:1.

14. Ubel PA, Asch DA. Creating value in health by understanding and overcoming resistance to de-innovation. Health Aff (Millwood). 2015;34(2):239-244.

15. Powell AA, Bloomfield HE, Burgess DJ, Wilt TJ, Partin MR. A conceptual frame work for understanding and reducing overuse by primary care providers. Med Care Res Rev. 2013;70(5):451-472.

16. Nassery N, Segal JB, Chang E, Bridges JF. Systematic overuse of healthcare services: a conceptual model. Appl Health Econ Health Policy. 2015;13(1):1-6.

17. Segal JB, Nassery N, Chang HY, Chang E, Chan K, Bridges JF. An index for measuring overuse of health care resources with Medicare claims. Med Care. 2015;53(3):230-236

18. Reschovsky JD, Rich EC, Lake TK. Factors contributing to variations in physicians' use of evidence at the point of care: a conceptual model. J Gen Intern Med. 2015;30(suppl 3):S555-S561.

19. Feinstein AR, Horwitz RI. Problems in the "evidence" of "evidence-based medi cine." Am J Med. 1997;103(6):529-535.

20. Makarov DV, Soulos PR, Gold HT, et al. Regional-level correlations in inappropriate imaging rates for prostate and breast cancers: potential implications for the Choosing Wisely campaign. JAMA Oncol. 2015;1(2):185-194.

21. Romano MJ, Segal JB, Pollack CE. The association between continuity of care an the overuse of medical procedures. JAMA Intern Med. 2015;175(7):1148-1154

22. Bayliss EA, Ellis JL, Shoup JA, Zeng C, McQuillan DB, Steiner JF. Effect of con tinuity of care on hospital utilization for seniors with multiple medical conditions in an integrated health care system. Ann Fam Med. 2015;13(2):123-129.

23. Chaiyachati $\mathrm{KH}$, Gordon $\mathrm{K}$, Long $\mathrm{T}$, et al. Continuity in a VA patient-centered medical home reduces emergency department visits. PloS One. 2014;9(5):e96356.

24. Underhill ML, Kiviniemi MT. The association of perceived provider-patient com munication and relationship quality with colorectal cancer screening. Health Educ Behav. 2012;39(5):555-563

25. Legare F, Labrecque M, Cauchon M, Castel J, Turcotte S, Grimshaw J. Training family physicians in shared decision-making to reduce the overuse of an tibiotics in acute respiratory infections: a cluster randomized trial. CMAJ. 2012;184(13):E726-E734

26. PerryUndum Research/Communication; for ABIM Foundation. Unnecessary Test and Procedures in the Health Care System: What Physicians Say About the Problem, the Causes, and the Solutions: Results From a National Survey of Physicians. http://www. choosingwisely.org/wp-content/uploads/2015/04/Final-Choosing-Wisely-Sur vey-Report.pdf. Published May 1, 2014. Accessed July 8, 2016.

27. Corallo AN, Croxford R, Goodman DC, Bryan EL, Srivastava D, Stukel TA. A systematic review of medical practice variation in OECD countries. Health Policy. 2014;114(1):5-14

28. Cutler D, Skinner JS, Stern AD, Wennberg DE. Physician Beliefs and Patient Preferences: A New Look at Regional Variation in Health Care Spending. NBER Working Paper No. 19320. Cambridge, MA: National Bureau of Economic Research; 2013 http://www.nber.org/papers/w19320. Published August 2013. Accessed July 8, 2016

29. Sirovich BE, Lipner RS, Johnston M, Holmboe ES. The association between residency training and internists' ability to practice conservatively. JAMA Intern Med. 2014;174(10):1640-1648.

30. Huttner B, Goossens H, Verheij T, Harbarth S. Characteristics and outcomes of public campaigns aimed at improving the use of antibiotics in outpatients in high-income countries. Lancet Infect Dis. 2010;10(1):17-31.

31. Perz JF, Craig AS, Coffey CS, et al. Changes in antibiotic prescribing for children after a community-wide campaign. JAMA. 2002;287(23):3103-3109.

32. Sabuncu E, David J, Bernede-Bauduin C, et al. Significant reduction of antibiotic use in the community after a nationwide campaign in France, 2002-2007. PLoS Med. 2009;6(6):e1000084.

33. Flodgren G, Eccles MP, Shepperd S, Scott A, Parmelli E, Beyer FR. An overview of reviews evaluating the effectiveness of financial incentives in changing healthcare professional behaviours and patient outcomes. Cochrane Database Syst Rev. 2011; (7):CD009255.

34. Yoon J, Rose DE, Canelo I, et al. Medical home features of VHA primary care clinics and avoidable hospitalizations. J Gen Intern Med. 2013;28(9):1188-1194.

35. Gonzales R, Anderer T, McCulloch CE, et al. A cluster randomized trial of decision support strategies for reducing antibiotic use in acute bronchitis. JAMA Intern Med. 2013;173(4):267-273.

36. Davis MM, Balasubramanian BA, Cifuentes M, et al. Clinician staffing, scheduling, and engagement strategies among primary care practices delivering integrated care. J Am Board Fam Med. 2015;28(suppl 1):S32-S40.

37. Dine CJ, Miller J, Fuld A, Bellini LM, Iwashyna TJ. Educating physicians-in-training about resource utilization and their own outcomes of care in the inpatient setting. J Grad Med Educ. 2010;2(2):175-180.

38. Elligsen M, Walker SA, Pinto R, et al. Audit and feedback to reduce broad-spectrum antibiotic use among intensive care unit patients: a controlled interrupted time series analysis. Infect Control Hosp Epidemiol. 2012;33(4):354-361.

39. Gerber JS, Prasad PA, Fiks AG, et al. Effect of an outpatient antimicrobial stewardship intervention on broad-spectrum antibiotic prescribing by primary care pediatricians: a randomized trial. JAMA. 2013;309(22):2345-2352.

40. Taggart LR, Leung E, Muller MP, Matukas LM, Daneman N. Differential outcome of an antimicrobial stewardship audit and feedback program in two intensive care units: a controlled interrupted time series study. BMC Infect Dis. 2015;15:480.

41. Hughes DR, Sunshine JH, Bhargavan M, Forman H. Physician self-referral for imaging and the cost of chronic care for Medicare beneficiaries. Med Care. 2011;49(9):857-864.

42. Ryskina KL, Pesko MF, Gossey JT, Caesar EP, Bishop TF. Brand name statin prescribing in a resident ambulatory practice: implications for teaching cost-conscious medicine. J Grad Med Educ. 2014;6(3):484-488

43. Bhatia RS, Milford CE, Picard MH, Weiner RB. An educational intervention reduces the rate of inappropriate echocardiograms on an inpatient medical service. JACC Cardiovasc Imaging. 2013;6(5):545-555.

44. Grimshaw JM, Thomas RE, MacLennan G, et al. Effectiveness and efficiency of guideline dissemination and implementation strategies. Health Technol Assess. 2004;8(6):iii-iv, 1-72.

45. Wilson I, Cowin LS, Johnson M, Young H. Professional identity in medical students: pedagogical challenges to medical education. Teach Learn Med. 2013;25(4):369-373.

46. Berger Z, Flickinger TE, Pfoh E, Martinez KA, Dy SM. Promoting engagement by patients and families to reduce adverse events in acute care settings: a systematic review. BMJ Qual Saf. 2014;23(7):548-555.

47. Dykes PC, Stade D, Chang F, et al. Participatory design and development of a patient-centered toolkit to engage hospitalized patients and care partners in their plan of care. AMIA Annu Symp Proc. 2014;2014:486-495.

48. Coxeter P, Del Mar CB, McGregor L, Beller EM, Hoffmann TC. Interventions to facilitate shared decision making to address antibiotic use for acute respiratory infections in primary care. Cochrane Database Syst Rev. 2015;(11):CD010907.

49. Stacey D, Legare F, Col NF, et al. Decision aids for people facing health treatment or screening decisions. Cochrane Database Syst Rev. 2014;(1):CD001431.

50. Bank AJ, Gage RM. Annual impact of scribes on physician productivity and revenue in a cardiology clinic. Clinicoecon Outcomes Res. 2015;7:489-495.

51. Lyles CR, Sarkar U, Schillinger D, et al. Refilling medications through an online patient portal: consistent improvements in adherence across racial/ethnic groups. J Am Med Inform Assoc. 2016;23(e1):e28-e33.

52. Kruse CS, Bolton K, Freriks G. The effect of patient portals on quality outcomes and its implications to meaningful use: a systematic review. J Med Internet Res. 2015;17(2):e44.

53. Smith CD. Teaching high-value, cost-conscious care to residents: the Alliance for Academic Internal Medicine-American College of Physicians curriculum. Ann Intern Med. 2012;157(4):284-286.

54. Redberg RF. Less is more. Arch Intern Med. 2010;170(7):584

55. Coory MD, Fagan PS, Muller JM, Dunn NA. Participation in cervical cancer screening by women in rural and remote Aboriginal and Torres Strait Islander communities in Queensland. Med J Aust. 2002;177(10):544-547.

56. Schwartz LM, Woloshin S, Fowler FJ Jr, Welch HG. Enthusiasm for cancer screening in the United States. JAMA. 2004;291(1):71-78.

57. Kressin NR, Lin MY. Race/ethnicity, and Americans' perceptions and experiences of over- and under-use of care: a cross-sectional study. BMC Health Serv Res. 2015;15:443.

58. Natale JE, Joseph JG, Rogers AJ, et al. Cranial computed tomography use among children with minor blunt head trauma: association with race/ethnicity. Arch Pe- 
diatr Adolesc Med. 2012;166(8):732-737.

59. Haggerty J, Tudiver F, Brown JB, Herbert C, Ciampi A, Guibert R. Patients' anx iety and expectations: how they influence family physicians' decisions to order cancer screening tests. Can Fam Physician. 2005;51:1658-1659.

60. Hoffmann TC, Del Mar C. Patients' expectations of the benefits and harms of treatments, screening, and tests: a systematic review. JAMA Intern Med. 2015;175(2):274-286

61. Sah S, Elias P, Ariely D. Investigation momentum: the relentless pursuit to resolve uncertainty. JAMA Intern Med. 2013;173(10):932-933.

62. Colla CH, Morden NE, Sequist TD, Schpero WL, Rosenthal MB. Choosing Wisely: prevalence and correlates of low-value health care services in the United States. J Gen Intern Med. 2015;30(2):221-228.

63. Earle CC, Landrum MB, Souza JM, Neville BA, Weeks JC, Ayanian JZ. Aggres siveness of cancer care near the end of life: is it a quality-of-care issue? J Clin Oncol. 2008;26(23):3860-3866

64. McWilliams JM, Dalton JB, Landrum MB, Frakt AB, Pizer SD, Keating NL. Geographic variation in cancer-related imaging: Veterans Affairs health care system versus Medicare. Ann Intern Med. 2014;161(11):794-802.

65. Birkmeyer JD, Reames BN, McCulloch P, Carr AJ, Campbell WB, Wennberg JE. Understanding of regional variation in the use of surgery. Lancet. 2013;382(9898):1121-1129.

66. Pearson SD, Goldman L, Orav EJ, et al. Triage decisions for emergency depart ment patients with chest pain: do physicians' risk attitudes make the difference? J Gen Intern Med. 1995;10(10):557-564.

67. Tubbs EP, Elrod JA, Flum DR. Risk taking and tolerance of uncertainty: implications for surgeons. J Surg Res. 2006;131(1):1-6.

68. Zaat JO, van Eijk JT. General practitioners' uncertainty, risk preference, and use of laboratory tests. Med Care. 1992;30(9):846-854.
69. Barnato AE, Tate JA, Rodriguez KL, Zickmund SL, Arnold RM. Norms of decision making in the ICU: a case study of two academic medical centers at the extremes of end-of-life treatment intensity. Intensive Care Med. 2012;38(11):1886-1896.

70. Fisher ES, Wennberg JE, Stukel TA, et al. Associations among hospital capacity, utilization, and mortality of US Medicare beneficiaries, controlling for sociodemographic factors. Health Serv Res. 2000;34(6):1351-1362.

71. Yasaitis LC, Bynum JP, Skinner JS. Association between physician supply, local practice norms, and outpatient visit rates. Med Care. 2013;51(6):524-531.

72. Chen C, Petterson S, Phillips R, Bazemore A, Mullan F. Spending patterns in region of residency training and subsequent expenditures for care provided by practicing physicians for Medicare beneficiaries. JAMA. 2014;312(22):2385-2393.

73. Ryskina KL, Smith CD, Weissman A, et al. U.S. internal medicine residents' knowledge and practice of high-value care: a national survey. Acad Med. 2015;90(10):1373-1379.

74. Khullar D, Chokshi DA, Kocher R, et al. Behavioral economics and physician compensation-promise and challenges. N Engl J Med. 2015;372(24):2281-2283.

75. Landon BE, Reschovsky J, Reed M, Blumenthal D. Personal, organizational, and market level influences on physicians' practice patterns: results of a national survey of primary care physicians. Med Care. 2001;39(8):889-905.

76. Fanari Z, Abraham N, Kolm P, et al. Aggressive measures to decrease "door to balloon" time and incidence of unnecessary cardiac catheterization: potential risks and role of quality improvement. Mayo Clin Proc. 2015;90(12):1614-1622.

77. Kerr EA, Lucatorto MA, Holleman R, Hogan MM, Klamerus ML, Hofer TP. Monitoring performance for blood pressure management among patients with diabetes mellitus: too much of a good thing? Arch Intern Med. 2012;172(12):938-945.

78. Verhofstede R, Smets T, Cohen J, Costantini M, Van Den Noortgate N, Deliens L. Implementing the care programme for the last days of life in an acute geriatric hospital ward: a phase 2 mixed method study. BMC Palliat Care. 2016;15:27. 